\title{
Association of Psychological Distress and Cardiovascular Disease among Adult USA Population
}

Michael G. McFarlane ${ }^{1}$, Emmanuel Valery ${ }^{2,3}$ and Moro O. Salifu ${ }^{3^{*}}$

${ }^{1}$ School of Public Health, State University of New York, Downstate Health Science University, Brooklyn, NY 11203, USA

${ }^{2}$ LaSante Health, 672 Parkside Ave, Brooklyn, NY 11226, USA

${ }^{3}$ Department of Medicine, State University of New York, Downstate Health Science University, Brooklyn, NY 11203, USA

Abstract

Background: Cardiovascular disease (CVD) is the major cause of mortality and morbidity among the adult USA population. Major cardiovascular risk factors include age, obesity, hypertension, hypercholesterolemia, diabetes, and chronic kidney disease (CKD) with both diabetes and CKD being considered CVD risk equivalent. Psychological distress is known to be associated with diverse health outcomes. We aim to assess the relationship between psychological distress and cardiovascular disease among adult USA population.

Materials \& Methods: Data was analyzed from National Health Interview Survey (NHIS) administered by the CDC's National Center for Health Statistics (NCHS).The NHIS samples non-institutionalized American civilians by household following a multi-stage area probability design. The survey included Kessler 6, a standardized psychological distress scale. SPSS ${ }^{\circ}$ version 26 was used for analysis which included utilizing both the t-test and ANOVA for continuous variables and the Chi-squared analysis for categorical variables. A logistic regression model was developed to estimate the odds ratio and the strength of association between psychological distress and cardiovascular risk factors, coronary heart disease and stroke. Data is presented as the mean value \pm SEM unless otherwise specified.

Results: The analysis included 284,497 respondents with 3.6\% of the US representative sample reporting psychological distress with a mean age of $48.09 \pm 0.16$. Psychological distress was more common among age group 45-64 years, women, Hispanics and Blacks, alcoholic drinkers, those without a high school diploma, and those below the poverty level. The unadjusted odds ratio for myocardial infarction among those with psychological distress was $2.6(2.45-2.8395 \% \mathrm{CI}), \mathrm{p}<0.01$. The unadjusted odds ratio for stroke among those with psychological distress was 3.1 (2.88-3.34 95\% CI), p<0.01. After adjusting for age, BMI, diabetes, hypertension, hypercholesterolemia, smoking and chronic kidney disease, the odds ratio of myocardial infarction among the psychologically distressed was $1.96(1.66-2.3195 \% \mathrm{CI}), \mathrm{p}<0.01$. The adjusted odds ratio for stroke was $2.56(2.18-3.0195 \% \mathrm{CI}) \mathrm{p}<0.01$.

Conclusion: Psychological distress is associated with a substantially higher risk of myocardial infarction and stroke independent of the traditional cardiovascular disease risk factors and is highly prevalent among ethnic minorities and disadvantaged socioeconomic groups. Further research is needed to develop effective interventions to manage psychological distress and decrease the disproportionately higher rates of cardiovascular disease among vulnerable populations.

\section{Introduction}

Psychological distress is defined as a state of emotional suffering associated with stressors and demands that are difficult to cope with in daily life [1]. It is known to be associated with adverse health outcomes in various disease states and among different populations $[2,3]$. Previous work indicates that psychological distress is associated with a 53\% increased risk of hypertension after controlling for multiple risk factors of high blood pressure among the psychologically distressed adult USA population [3]. Cardiovascular disease (CVD), including coronary heart disease (CHD) and stroke, is the leading cause of death for men, women, and people of most racial and ethnic groups in the United States [4]. The association between psychological distress and cardiovascular disease has not been extensively studied. The aim of this study is to examine the association of psychological distress and cardiovascular disease among the adult USA population based on data from the National Health Interview Survey (NHIS). NHIS is a principal source of information on the health of the civilian noninstitutionalized population of the United States [5]. We used data from 2004-2013 that included an assessment of psychological distress using the standardized Kessler-6 questionnaire [6]

\section{Publication History:}

Received: December 05, 2020 Accepted: January 05, 2021 Published: January 07, 2021

\section{Keywords:}

\section{Psychological distress,}

Cardiovascular disease, Kessler psychological distress scale, Hypertension, Obesity, Diabetes, Hypercholesterolemia, Race, Ethnicity, Health Disparity

\section{Materials \& Methods}

Data was analyzed from the National Health Interview Survey (NHIS) administered by the CDC's National Center for Health Statistics (NCHS) from 2004-2013. NHIS includes noninstitutionalized American civilians sampled by household following a multi-stage area probability design. The survey included Kessler 6, a standardized psychological distress scale that is an abbreviated version of Kessler 10, which was used for screening and assessment of severity of anxiety disorders.

SPSS $^{\star}$ version 26 was used for assessing measures of central tendency, and for analysis utilizing t-test and ANOVA for continuous "Corresponding Author: Prof. Moro O. Salifu, Chairman, Department of Medicine, State University of New York, Downstate Health Science University, Brooklyn, NY USA-11203; E-mail: Moro.Salifu@downstate.edu

Citation: McFarlane MG, Valery E, Salifu MO (2021) Association of Psychologica Distress and Cardiovascular Disease among Adult USA population. Int J Clin Res Trials 6: 156. doi: https://doi.org/10.15344/2456-8007/2021/156

Copyright: (c) 2020 McFarlane et al. This is an open-access article distributed under the terms of the Creative Commons Attribution License, which permits unrestricted use, distribution, and reproduction in any medium, provided the original author and source are credited. 
Citation: McFarlane MG, Valery E, Salifu MO (2021) Association of Psychological Distress and Cardiovascular Disease among Adult USA population. Int J Clin Res Trials 6: 156. doi: https://doi.org/10.15344/2456-8007/2021/156

Page 2 of 5

variables. Data is presented as the mean \pm SEM unless otherwise specified.

Chi-squared analysis was used for categorical variables. A logistic regression model was used to estimate the odds ratio and the strength of association between psychological distress and cardiovascular risk factors, myocardial infarction, and stroke. Both the unadjusted and adjusted odds ratio were calculated. The adjusted odds ratios adjusted for CVD risk factors including: age, Body mass index, Diabetes, Hypertension, Hypercholesterolemia, Smoking, Chronic Kidney Disease.

\section{Results}

Of the 284,497 respondents to the Kessler Psychological Distress Scale (K6) involved in our study representing the adult USA population, 10,218 (3.6\%) reported psychological distress with a mean age of (years \pm SEM) $(48.09 \pm 0.16$ vs. $47.69 \pm 0.04, \mathrm{p}<0.05)$, for psychological distress vs. non-psychologically distressed groups respectively. Psychological distress tended to be more common among age group 45-64 years (4.4\%) compared to those 18-44 (2.8\%) and those more than 65 years of age $(2.6 \%), \mathrm{p}<0.01$ (Table 1 ). Psychological distress was more prevalent among women compared to men $(4.2 \%$ vs. $2.9 \%$ for women and men respectively, $\mathrm{p}=0.01)$. Hispanics and Blacks had higher percentage of psychological distress $(4.1 \%$ vs. $4.0 \%$ vs. $3.5 \%$ vs. $1.9 \%, \mathrm{p}<0.01$ ) for Hispanics, Blacks, Whites, and Asians respectively. Psychological distress was more prevalent among those without high school degree $(7.0 \%$ vs. $3.0 \%, \mathrm{p}<0.01)$. The rate of psychological distress as it relates to alcohol drinking was $(5.9 \%$ vs. $3.1 \%$ vs. $3.4 \%, \mathrm{p}<0.01$ ) for former drinkers, never drinkers and current drinkers respectively. Psychological distress was 3.4 times as prevalent among those who are below the federal poverty level (FPL), compared to those above the FPL $(2.6 \%$ Vs $8.9 \%, \mathrm{P}<0.01)$ for those above and below the FPL respectively.

For risk factors of Cardiovascular disease (CVD) (Table 2), current smokers have greater psychological distress than former smokers and never smokers $(7.5 \%$ vs. $3.2 \%$ vs. $2.4 \%, \mathrm{p}<0.01$ for current, former and never smokers respectively. There was no significant difference in the prevalence of psychological distress by exercise category $(2.1 \%$ vs. $1.8 \%$. vs. $1.8 \%, \mathrm{p}=0.69)$ for inactive, insufficiently active, and sufficiently active individuals respectively. Obesity (BMI $>30 \mathrm{~kg} / \mathrm{m}^{2}$ ) was associated with higher prevalence of psychological distress $(4.9 \%$ vs. $2.9 \%$ vs. $2.9 \%, \mathrm{p}<0.01)$ for obese vs. overweight (BMI 25-25.9) vs. normal weight (BMI 18.5-24.9) individuals. Hypertension was more than twice as prevalent among those with psychological distress compared to those without psychological distress (5.6\% vs. $2.7 \%$, $\mathrm{p}<0.01)$. Psychological distress was more prevalent among those with hypercholesterolemia compared to those with normal cholesterol $(4.7 \%$ vs. $2.7 \%, \mathrm{p}<0.01)$.

Psychological distress was more prevalent among those with coronary heart disease (CHD) (Table 3$)(8.5 \%$ vs. $3.4 \%, \mathrm{p}<0.01)$, for $\mathrm{CHD}$ and no-CHD groups respectively. Psychological distress was nearly three times as prevalent among those with stroke $(9.8 \%$ vs. $3.4 \%, \mathrm{p}<0.01)$ for stroke and non-stroke population respectively. Chronic kidney disease (CKD) (weak/failing kidney) was associated with four times rate of psychological distress ( $14.2 \%$ vs. $3.4 \%, \mathrm{p}<0.01)$ for CKD and non-CKD population respectively. Using the logistic regression model, the unadjusted odds ratio (Table $4 \mathrm{~A}$ ) for myocardial

\begin{tabular}{|c|c|c|c|c|c|}
\hline \multirow[b]{2}{*}{ Age group, years } & \multicolumn{2}{|c|}{ No Psych Distress $(\mathrm{n}=274279)$} & \multicolumn{2}{|c|}{ Psych Distress $(\mathrm{n}=10218)$} & \multirow[t]{2}{*}{ p-value } \\
\hline & Number & $\%$ & Number & $\%$ & \\
\hline $18-44$ & 78411 & 97.2 & 2268 & 2.8 & \multirow[t]{3}{*}{.0001} \\
\hline $45-64$ & 140077 & 95.4 & 6465 & 4.4 & \\
\hline$\geq 65$ & 55791 & 97.4 & 1485 & 2.6 & \\
\hline \multicolumn{6}{|l|}{ Sex } \\
\hline Male (170687/48.9\%) & 122236 & 97.1 & 3596 & 2.9 & \multirow[t]{2}{*}{0.01} \\
\hline Female (199094/51.9\%) & 152043 & 95.8 & 6622 & 4.2 & \\
\hline \multicolumn{6}{|l|}{ Race } \\
\hline Non-Hispanic Whites & 166786 & 96.5 & 5963 & 3.5 & \multirow[t]{4}{*}{0.01} \\
\hline Non-Hispanic Blacks & 41680 & 96.0 & 1744 & 4.0 & \\
\hline Asians & 14611 & 98.1 & 282 & 1.9 & \\
\hline Hispanics & 48465 & 95.9 & 2067 & 4.1 & \\
\hline \multicolumn{6}{|l|}{ High School } \\
\hline No High School Degree & 39404 & 93.0 & 2946 & 7.0 & \multirow[t]{2}{*}{0.01} \\
\hline High School Degree & 233111 & 97.0 & 7202 & 3.0 & \\
\hline \multicolumn{6}{|l|}{ Poverty } \\
\hline Above federal poverty level & 198966 & 97.4 & 5407 & 2.6 & \multirow[t]{2}{*}{0.01} \\
\hline Below federal poverty level & 38253 & 91.1 & 3743 & 8.9 & \\
\hline \multicolumn{6}{|l|}{ Alcohol } \\
\hline Never Drinker & 62494 & 96.6 & 2202 & 3.4 & \multirow[t]{3}{*}{0.01} \\
\hline Former Drinker & 40667 & 94.1 & 2565 & 5.9 & \\
\hline Current Drinker & 166196 & 96.9 & 5275 & 3.1 & \\
\hline
\end{tabular}


Citation: McFarlane MG, Valery E, Salifu MO (2021) Association of Psychological Distress and Cardiovascular Disease among Adult USA population. Int J Clin Res Trials 6: 156. doi: https://doi.org/10.15344/2456-8007/2021/156

Page 3 of 5

\begin{tabular}{|c|c|c|c|c|c|}
\hline & \multicolumn{2}{|c|}{ No Psychological Distress $(\mathrm{n}=274279)$} & \multicolumn{2}{|c|}{ Psychological Distress $(\mathrm{n}=10218)$} & P-Value \\
\hline \multicolumn{6}{|c|}{ D } \\
\hline Never Smokes & 162141 & 97.6 & 4020 & 2.4 & \multirow[t]{2}{*}{$<0.01$} \\
\hline Current Smoker & 51366 & 92.5 & 4185 & 7.5 & \\
\hline \multicolumn{6}{|l|}{ Exercise } \\
\hline Active ( $\geq 150$ mins/week) & 37239 & 98.2 & 680 & 1.8 & 0.69 \\
\hline \multicolumn{6}{|l|}{ Obesity by Body Mass Index $\left(\mathrm{kg} / \mathrm{m}^{2}\right)$} \\
\hline Normal Weight (BMI 18.5-24.9) & 89981 & 97.1 & 2711 & 2.9 & \multirow[t]{2}{*}{$<0.01$} \\
\hline Overweight (BMI 25-29.9) & 90480 & 97.1 & 2676 & 2.9 & \\
\hline \multicolumn{6}{|l|}{ Diabetes } \\
\hline No Diabetes & 246165 & 96.8 & 8152 & 3.2 & \multirow[t]{2}{*}{$<0.01$} \\
\hline Diabetes & 24636 & 93.2 & 1807 & 6.8 & \\
\hline \multicolumn{6}{|l|}{ Hypercholesterolemia } \\
\hline No hypercholesterolemia & 52020 & 97.3 & 1441 & 2.7 & \multirow[t]{2}{*}{$<0.01$} \\
\hline hypercholesterolemia & 19829 & 95.3 & 988 & 4.7 & \\
\hline
\end{tabular}

Table 2: Psychological Distress among USA population: Cardiometabolic Risk Factors.

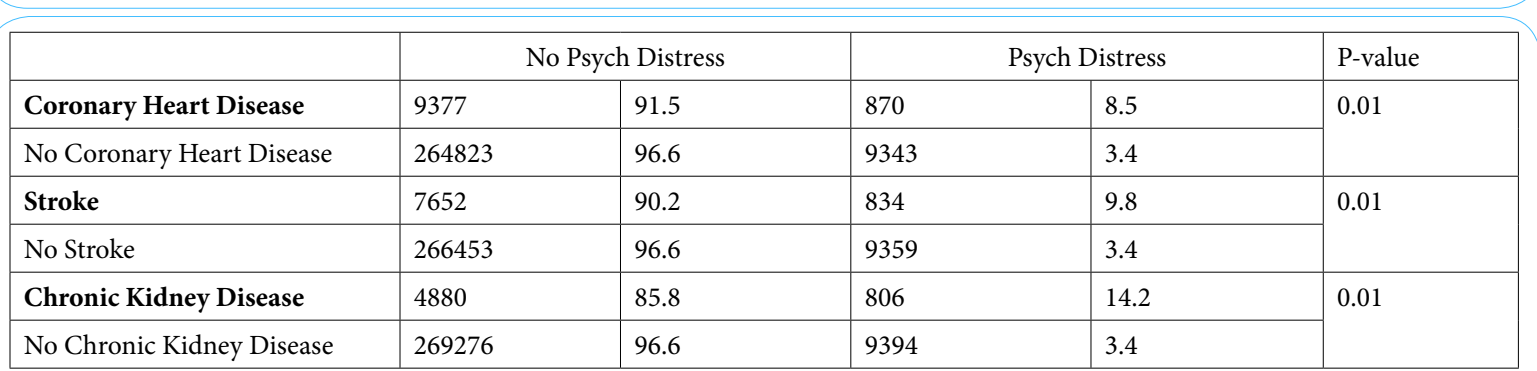

Table 3: Psychological distress among USA populations and Cardiovascular Disease.

\begin{tabular}{|l|l|l|l|}
\hline CVD & OR & $95 \%$ CI & P-value \\
\hline Myocardial Infarction & 2.6 & $2.45-2.83$ & $<0.01$ \\
\hline \multicolumn{2}{|l|}{} \\
\hline CVD & OR & $95 \%$ CI & P-value \\
\hline Stroke & 3.1 & $2.88-3.34$ & $<0.01$ \\
\hline
\end{tabular}

Table 4A: Unadjusted odds for Cardiovascular Disease (CVD) among Psychologically Distressed Persons.

\begin{tabular}{|l|l|l|l|l|}
\hline & Sig. & Exp(B) & 95\% C.I.for EXP(B) & Upper \\
\cline { 3 - 5 } & & & Lower & 2.313 \\
\hline Psychological Distress & .000 & 1.963 & 1.666 & 1.061 \\
\hline Age & .000 & 1.057 & 1.054 & 1.001 \\
\hline Body mass index & .210 & .998 & .995 & 2.189 \\
\hline Diabetes & .000 & 1.997 & 1.822 & 2.278 \\
\hline Hypertension & .000 & 2.066 & 1.873 & 2.326 \\
\hline Hypercholesterolemia & .000 & 2.131 & 1.952 & \\
\hline Never Smoker & & 1.00 & & 2.099 \\
\hline Former Smoker & .000 & 1.914 & 2.530 & 3.169 \\
\hline Current Smoker & .000 & 2.832 & 1.732 & 2.372 \\
\hline Chronic Kidney Disease & .000 & 2.027 & & \\
\hline Constant & .000 & .000 & & \\
\hline
\end{tabular}

Table 4B: Odds ratio for myocardial infarction in Psychological Distress, adjusted for Age, Body mass index, Diabetes, Hypertension,

Hypercholesterolemia, Smoking, Chronic Kidney Disease. 
Citation: McFarlane MG, Valery E, Salifu MO (2021) Association of Psychological Distress and Cardiovascular Disease among Adult USA population. Int J Clin Res Trials 6: 156. doi: https://doi.org/10.15344/2456-8007/2021/156

Page 4 of 5

\begin{tabular}{|l|l|l|l|l|}
\hline & Sig. & Exp(B) & 95\% C.I. for EXP(B) & Upper \\
\cline { 3 - 5 } & & & Lower & 3.015 \\
\hline Psychological Distress & .000 & 2.564 & 2.181 & 1.056 \\
\hline Age & .000 & 1.052 & 1.049 & 1.002 \\
\hline Body mass index & .343 & .998 & .995 & 2.051 \\
\hline Diabetes & .000 & 1.857 & 1.682 & 2.820 \\
\hline Hypertension & .000 & 2.532 & 2.274 & 1.624 \\
\hline Hypercholesterolemia & .000 & 1.481 & 1.350 & 1.456 \\
\hline Never Smoker & .000 & & & 2.248 \\
\hline Former Smoker & .000 & 1.319 & 1.195 & 2.361 \\
\hline Current Smoker & .000 & 1.995 & 1.771 & \\
\hline Chronic Kidney Disease & .000 & 2.000 & .001 & \\
\hline Constant & .000 & & \\
\hline
\end{tabular}

Table 4C: Odds ratio for stroke in Psychological Distress, after adjusting for Age, Body mass index, Diabetes, Hypertension, high

cholesterol, Smoking, Chronic Kidney Disease.

infarction in psychologically distressed persons was OR $=2.6$ 2.83), 95\% CI, P $<0.01$. The unadjusted odds ratio for stroke was OR $=3.1$ (2.9-3.3), 95\% CI, P <0.01. After adjusting for Age, Body mass index, Diabetes, Hypertension, high cholesterol, smoking, Chronic Kidney Disease, the adjusted OR for myocardial infarction (Table 4B) was $1.96(1.67-2.3) 95 \% \mathrm{CI}, \mathrm{P}<0.01$. The adjusted OR for stroke (Table $4 \mathrm{C})$ was $2.5(2.2-3.0) 95 \% \mathrm{CI}, \mathrm{P}<0.01$.

\section{Discussion}

The association between psychological distress, diabetes, hypertension, obesity as well as chronic kidney disease and consequently, CVD could be readily explained by elevated stress hormones that are known to have deleterious health effects. Abdominal obesity, a major risk factor for CVD and metabolic syndrome, is known to be associated with maladaptation to chronic environmental stress which is mediated by a dysregulation of neuroendocrine axes [7]. Chronic activation of the hypothalamic-pituitary-adrenal axis plays a major role in this context together with the stimulation of the sympathetic nervous system leading to chronic diseases including obesity and hypertension [7-10]. While counterregulatory hormones including glucagon, cortisol, growth hormone and catecholamines generally serve as a safeguard to hypoglycemia to counteract the effect of insulin, chronic elevation of these hormones has been shown to be deleterious and is associated with a diabetogenic effect and obesity $[11,12]$. This concept is readily demonstrable through the high prevalence of diabetes and hypertension in diseases associated with chronic increases in these hormones. For example, high prevalence of diabetes and hypertension is a common feature of Cushing's disease, which is characterized by chronic elevation of cortisol $[13,14]$. In patients with chronically high levels of growth hormone, such as those with acromegaly, there is a high prevalence of diabetes and hypertension $[15,16]$. These disorders are also associated with a high risk of CVD likely explainable by the chronically elevated cortisol in Cushing's disease [17] and growth hormone in acromegaly [18-20]. These data collectively provide a common soil hypothesis linking psychological distress with the elevated cardiovascular disease risk demonstrated in this study. The data also indicates the role of chronic elevation of stress hormones in the pathogenesis of CVD in adult USA population in this study. Research evidence suggests that atherosclerosis as measured by carotid medial thickness starts as early as adolescence and is linked to urinary free cortisol [21].
High prevalence of psychological distress and CVD among Hispanic and Black populations are readily explainable by the allostatic load caused by adverse socioeconomic factors linked to poverty which lead to worse health outcomes [22-24]. This study also demonstrated a significantly higher rate of psychological distress among women compared to men. This finding is likely a reflection of increased allostatic load among women that has been demonstrated in previous studies [25-27]. Furthermore, chronic activation of the sympathetic system leads to deleterious health effects including elevated blood pressure and blood glucose, and activation of the renin-angiotensinaldosterone system [28-30]. Finally, this study clearly demonstrated not only disparity in the risk factors of CVD among women, racial minorities and socioeconomically disadvantaged by population, but also heightened increase of CVD, the main killer of adult Americans. Effective interventions to treat and manage psychological stress among these vulnerable populations and to eliminate the accompanying healthcare disparities are greatly needed to improve the health, wellbeing and outcomes of CVD.

\section{Conclusion}

This study demonstrated a relationship between cardiovascular disease (myocardial infarction and stroke) and psychological distress. This association was strong and remained after adjusting for the multiple risk factors of CVD including age, obesity, diabetes, hypertension, dyslipidemia, chronic kidney disease and smoking. These are well-established risk factors for CVD and each of these risk factors are independently associated with psychological distress. This study also demonstrated that psychological distress is strongly associated with adverse sociodemographic factors such as poverty and low educational attainment. Psychological distress was also more prevalent among women and ethnic minorities such as Blacks and Hispanics. Further research is needed to confirm these findings and effective methods for management of psychological distress should be developed and employed in order to decrease cardiovascular disease among the most vulnerable populations.

\section{Acknowledgement}

This work is supported, in part, by the efforts of Dr. Moro O. Salifu MD, MPH, MBA, MACP, Professor and Chairman of Medicine through NIMHD Grant number S21MD012474. 
Citation: McFarlane MG, Valery E, Salifu MO (2021) Association of Psychological Distress and Cardiovascular Disease among Adult USA population. Int J Clin Res Trials 6: 156. doi: https://doi.org/10.15344/2456-8007/2021/156

Page 5 of 5

\section{Competing Interests}

The authors declare that they have no competing interests.

\section{References}

1. Arvidsdotter T, Marklund B, Kylén S, Taft C, Ekman I, et al. (2016) Understanding persons with psychological distress in primary health care. Scand J Caring Sci 30: 687-694.

2. Schmidt CB, Potter van Loon BJ, Vergouwen ACM, Snoek FJ, Honig A, et al (2018) Systematic review and meta-analysis of psychological interventions in people with diabetes and elevated diabetes-distress. Diabet Med.

3. Ojike N, Sowers JR, Seixas A, Ravenell J, Rodriguez-Figueroa G, et al. (2016) Psychological Distress and Hypertension: Results from the National Health Interview Survey for 2004-2013. Cardiorenal Med 6: 198-208.

4. Underlying Cause of Death, 1999-2019. Center for Disease Control.

5. National Health Interview Survey. Center for Disease Control.

6. Yiengprugsawan V, Kelly M, Tawatsupa B (2014) Kessler Psychological Distress Scale. In Encyclopedia of Quality of Life and Well-Being Research. Springer Netherlands: Dordrecht.

7. Pasquali R (2012) The hypothalamic-pituitary-adrenal axis and sex hormones in chronic stress and obesity: pathophysiological and clinical aspects. Ann NY Acad Sci 1264: 20-35.

8. van Rossum EF (2017) Obesity and cortisol: New perspectives on an old theme. Obesity 25: 500-501.

9. Morais JBS, Severo JS, Beserra JB, Soares de Oiveira AR, Cruz KJC, et al (2019) Association Between Cortisol, Insulin Resistance and Zinc in Obesity: a Mini-Review. Biol Trace Elem Res 191: 323-330.

10. Lopez-Pulido EI, Santos SRL, González-Sánchez GD, Becerra-Ruiz JS, Rivas-Delgado ME, et al. (2020) Association of Obesity with Depressive Symptomatology, Eating Habits, Interleukin-8 and Cortisol in a Young Population. Ecol Food Nutr.

11. Sarlak H, Akhan M, Cakar M, Kurt O, Arslan E, et al. (2014) Admission hyperglycemia may be the result of counterregulatory hormones during acute coronary syndrome events. Angiology 65: 160 .

12. Haigwood JT, Flores RM, Mazloumi R, Ngan G, Kelley KM, et al. (2000) Diabetogenic role of insulin's counterregulatory hormones in the isletectomized, diabetic goby. Endocrine 13: 273-280.

13. Mazziotti G, Gazzaruso C, Giustina A (2011) Diabetes in Cushing syndrome: basic and clinical aspects. Trends Endocrinol Metab 22: 499-506.

14. Mazziotti G, Formenti AM, Frara S, Maffezzoni F, Doga M, et al. (2017) Diabetes in Cushing Disease. Curr Diab Rep 17: 32.

15. Warncke K, Kummer S, Kann PH, Bergis D, Bollow E, et al. (2020) Cardivascular Risk Profile in Patients with Diabetes and Acromegaly or Cushing's Disease - Analysis from the DPV Database. Exp Clin Endocrinol Diabetes 128: 104110

16. Wani AA (2020) Acromegaly and Diabetes - A Hand in Glove Combination Neurol India 68: 1259-1260.

17. Whitworth JA, Mangos GJ, Kelly JJ (2000) Cushing, cortisol, and cardiovascular disease. Hypertension 36: 912-916.

18. Wolters TLC, Netea MG, Riksen NP, Hermus ARMM, Netea-Maier RT, et al. (2020) Acromegaly, inflammation and cardiovascular disease: a review. Rev Endocr Metab Disord 21: 547-568.

19. Lin YC, Yu WC, Kuo CS, Chen HS (2020) Growth hormone control and cardiovascular function in patients with acromegaly. J Chin Med Assoc

20. Kamenicky P, Maione L, Chanson P (2020) Cardiovascular complications of acromegaly. Ann Endocrinol.

21. Peppa-Patrikiou M, Scordili M, Antoniou A, Giannaki M, Dracopoulou M, et al. (1998) Carotid atherosclerosis in adolescents and young adults with IDDM. Relation to urinary endothelin, albumin, free cortisol, and other factors. Diabetes Care 21: 1004-1007.

22. Lunyera J, Stanifer JW, Davenport CA, Mohottige D, Bhavsar NA, et al. (2020) Life Course Socioeconomic Status, Allostatic Load, and Kidney Health in Black Americans. Clin J Am Soc Nephrol 15: 341-348.

23. Legato MJ (2010) The allostatic load: how stress makes us sick. Gend Med 7: $458-460$
24. Goldstein DS (2012) Stress, allostatic load, catecholamines, and other neurotransmitters in neurodegenerative diseases. Cell Mol Neurobiol 32: 661-666.

25. von Thiele $U$, Lindfors $P$, Lundberg $U$ (2006) Self-rated recovery from work stress and allostatic load in women. J Psychosom Res 61: 237-242.

26. Upchurch DM, Stein J, Greendale GA, Chyu L, Tseng CH, et al. (2015) A Longitudinal Investigation of Race, Socioeconomic Status, and Psychosocial Mediators of Allostatic Load in Midlife Women: Findings From the Study of Women's Health Across the Nation. Psychosom Med 77: 402-412.

27. Tan M, Mamun A, Kitzman H, Mandapati SR, Dodgen L, et al. (2017) Neighborhood Disadvantage and Allostatic Load in African American Women at Risk for Obesity-Related Diseases. Prev Chronic Dis 14: E119.

28. Jansen AS, Nguyen XV, Karpitskiy V, Mettenleiter TC, Loewy AD, et al. (1995) Central command neurons of the sympathetic nervous system: basis of the fight-or-flight response. Science 270: 644-646.

29. Goldstein DS (1996) The sympathetic nervous system and the 'fight-orflight' response: outmoded ideas? Mol Psychiatry 1: 95-97.

30. Curtis BM, O'Keefe Jr JH (2002) Autonomic tone as a cardiovascular risk factor: the dangers of chronic fight or flight. Mayo Clin Proc 77: 45-54. 